\title{
Meta-analysis: rapid infliximab infusions are safe
}

\author{
H. C. Neef*, M. P. Riebschleger ${ }^{\dagger} \&$ J. Adler*
}

*Division of Pediatric

Gastroenterology, Department of

Pediatrics and Communicable

Diseases, University of Michigan, Ann

Arbor, MI, USA.

†Division of Pediatric Rheumatology,

Department of Pediatrics and

Communicable Diseases, University of

Michigan, Ann Arbor, MI, USA.

\section{Correspondence to:}

Dr J. Adler, Division of Pediatric Gastroenterology, Department of

Pediatrics and Communicable

Diseases, University of Michigan,

1500 East Medical Center Drive, MPB

D5200, Box SPC5718, Ann Arbor, MI

48109-5718, USA.

E-mail: jeradler@umich.edu

\section{Publication data}

Submitted 29 December 2012

First decision 18 January 2013

Resubmitted 5 June 2013

Accepted 6 June 2013

EV Pub Online 1 July 2013

As part of AP\&T's peer-review process, a technical check of this meta-analysis was performed by Mr M. Siddiqui.

\section{SUMMARY}

\section{Background}

Infliximab is typically administered intravenously via 2 - to 3 -h duration infusions. Infusions are time-consuming and costly. Shorter duration infusions are administered at some centres. Limited safety data are available on shorter duration infusions.

\section{Aim}

To determine risk of infusion reaction associated with standard 2- to 3-h infusions vs. rapid infusions in patients receiving infliximab therapy for inflammatory bowel disease (IBD), rheumatoid arthritis, spondylarthopathy and psoriatic disease.

\section{Methods}

MEDLINE, Embase, and Web of Science were searched. Inclusion required human subjects, documentation of number of standard and rapid infliximab infusions and number of incident infusion reactions. Studies of overlapping populations were excluded. Three reviewers independently extracted data. Study quality was assessed. Relative risk (RR) was pooled using random effects models.

\section{Results}

We identified 10 studies comprising 13147 standard 2- to 3 -h and $8497 \leq 1$-h infliximab infusions. Nine studies reported the risk of infusion reaction in standard vs. 1-h infusions, demonstrating decreased RR of infusion reaction with 1 -h vs. standard infusions $(0.9 \%$ vs. $2.2 \%$ of infusions; $R R=0.48$, $P=0.009)$. Seven studies limited to IBD also demonstrated decreased risk of reaction $(\mathrm{RR}=0.49, P=0.002)$. Other comparisons demonstrated no difference in RR of reaction, including concomitant medication use $(P=0.30)$ or analysis limited to high and medium quality studies $(P=0.07)$.

\section{Conclusions}

Rapid infliximab infusions of $\leq 1$-h duration are not associated with increased risk of infusion reaction when compared to standard 2- to 3-h infusions in selected patients who previously tolerated three to four standard infusions. One-hour infusions will conserve health care resources and may lead to improved adherence and quality of life in patients receiving infliximab.

Aliment Pharmacol Ther 2013; 38: 365-376 


\section{H. C. Neef et al.}

\section{INTRODUCTION}

Infliximab is a tumour necrosis factor-alpha inhibitor that has decreased disease activity and improved quality of life for adults and children with inflammatory bowel disease (IBD) and other inflammatory conditions (rheumatoid arthritis, spondylarthropathy and psoriatic disease). ${ }^{1-5}$ Infliximab is available only as an intravenous preparation that is typically administered over $2-3 \mathrm{~h} .{ }^{6,7}$ Despite the benefits of infliximab, standard (2- to 3-h duration) infliximab infusion represents a significant burden in time away from school and/or work. In addition, routine infliximab administration consumes valuable health care resources because space, time and staff for infusion administration are limited and costly., 9

Infusion reactions associated with infliximab administration occur with $2-3 \%$ of infusions. ${ }^{10}$ Certain factors may modify the risk of infusion reaction occurrence. Patients receiving infliximab maintain better disease control and have a lower risk of infusion reaction if infliximab is routinely administered at a dosing interval of 8 weeks or less, rather than at intervals greater than 12 weeks. ${ }^{11,12}$ Infusion reactions also occur less frequently in patients receiving concomitant immunomodulator therapy. ${ }^{13}$ Premedication with single dose steroid, antihistamine, and/or acetaminophen just prior to the infusion inconsistently demonstrates a decreased risk of infusion reaction. ${ }^{14}$

Rapid (1-h or shorter duration) infliximab infusions have been implemented in few institutions. ${ }^{15-27}$ Limited published data are available on the safety of rapid infliximab infusions regarding the risk of infusion reaction. To assess this risk, we performed a systematic review of the literature and meta-analysis to identify studies of infusion reaction occurrence associated with standard infliximab infusions compared to rapid infusions. We aimed to determine if rapid 1-h duration infliximab infusions would be associated with increased risk of infusion reaction compared with standard 2- to 3-h duration infliximab infusions. We hypothesised that rapid infliximab infusions would not have greater risk of infusion reaction compared with standard duration infusions.

\section{MATERIALS AND METHODS}

\section{Search Strategies}

We searched MEDLINE (Ovid Technologies, New York, NY, USA), Embase (Elsevier, New York, NY, USA), and ISI Web of Science (Thomson Reuters, New York, NY, USA). All databases were searched from inception to 28 March 2013 according to the MOOSE guidelines. ${ }^{28}$
The MEDLINE search strategy used Medical Subject Headings (US National Library of Medicine) and free text words, and was as follows: [('exp Tumor Necrosis Factor-alpha/Administration \& Dosage, Adverse Effects, Antagonists \& Inhibitors, Drug Effects, Pharmacokinetics, Pharmacology, Standards, Therapeutic Use, Toxicity' or 'infliximab.mp' or 'remicade.mp') and ('infusion.mp' or 'exp Infusions, Intravenous/') and ('rate.mp' or 'administration rate.mp' or 'accelerated.mp' or 'rapid.mp')], with results limited to humans.

The Embase search strategy was as follows: [(rapid or rate or accelerat*) and (administr* or 'infusion' or 'intravenous drug administration') and (infliximab or remicade or 'tumor necrosis factor alpha inhibitor')], with results limited to humans.

The ISI Web of Science search strategy was as follows: [(rapid or rate or accelerat*) and (administr* or infusion or intravenous or IV) and (infliximab or remicade or 'tumor necrosis factor alpha inhibitor*' or 'TNF-alpha inhibitor*')].

The search was not limited by language. We then reviewed the bibliographies of included studies to identify any additional relevant studies.

\section{Study Selection}

Inclusion required documentation of human subjects, number of standard and rapid infliximab infusions and number of infusion reactions that occurred in each group. Studies were excluded if different durations of infusions were not compared and/or adequately described. We attempted to contact multiple authors to obtain missing data. In studies with overlapping or duplicate subject populations based on study location and/or authorship, the most recent publication was included. All others were excluded. Two independent reviewers (HCN, MPR) read the titles and abstracts of all studies identified in the search. Each reviewer applied exclusion and inclusion criteria independently. The full text of each study that was not excluded based on the abstract alone was then reviewed. All discrepancies were resolved by consensus with 100\% consensus achieved.

\section{Data Extraction}

Three independent reviewers (HCN, MPR, JA) extracted the following data from the included relevant studies: author, publication year, type of control group, number of patients, age range, underlying disease, concomitant medication use, documentation of tolerance of or prior infusion reaction to standard duration infliximab infusions, infusion duration, dosage, administration of single 
dose premedication just prior to the infusion, and number and type of infusion reactions (severity, delayed vs. acute). All discrepancies were resolved by consensus with $100 \%$ consensus achieved.

\section{Quality Assessment}

We assessed the quality of the included studies using the Newcastle-Ottawa quality scale for cohort studies. ${ }^{29} \mathrm{We}$ also included four relevant ad hoc quality criteria, including the following: (i) peer review of the final publication; (ii) documentation of use or non-use of concomitant immunomodulators and/or steroids; (iii) documentation of the use or non-use of single dose premedication prior to infusions; and (iv) disclosure of conflict of interest resulting from author-industry financial relationships.

\section{Meta-analyses}

The primary outcome measured (per-infusion analysis) was the risk of infusion reaction following administration of standard infliximab infusions compared to 1-h infusions where risk was calculated as the number of infusion reactions per infusion administered in each treatment arm. The primary outcome was also calculated to determine the risk of infusion reaction per patient with the analysis weighted by the number of infusions administered to each patient in each treatment arm (per-patient analysis).

Subgroup analyses were performed for additional outcomes reported, including analyses of the risk of: (i) infusion reaction in standard vs. 30- to 45-min infliximab infusions; (ii) infusion reaction in all patients who did or did not routinely receive premedication prior to infusions comparing standard vs. 1-h infusions; (iii) infusion reaction in patients who concomitantly received one or more immunomodulator (including mercaptopurine, methotrexate, azathioprine and/or leflunomide) and/or oral steroids comparing standard vs. 1-h infusions; (iv) severe infusion reaction with standard vs. 1-h infusions; (v) delayed infusion reaction with standard vs. 1-h infusions; (vi) infusion reaction in subgroups of patients with IBD or in subgroups of patients with other inflammatory conditions with standard vs. 1-h infusions; (vii) infusion reaction in subgroups of patients receiving high dose $(5-10 \mathrm{mg} / \mathrm{kg})$ vs. low dose $(<5 \mathrm{mg} / \mathrm{kg})$ infliximab, each comparing standard vs. 1-h infusions; and (viii) infusion reaction limited to high and medium quality studies as defined by the Newcastle-Ottawa quality scale for cohort studies. A priori prespecified subgroup analyses included (ii), (iii) and (vi). After study selection and review, post hoc subgroup analyses (i), (iv), (v), (vii) and (viii) were added based on the available data in the studies. All meta-analyses were completed in accordance with preferred reporting items for systematic reviews and meta-analyses (PRISMA) guidelines. ${ }^{30}$

\section{Sensitivity Analyses}

Sensitivity analyses were performed by three methods to confirm the stability of the per-infusion primary outcome, the risk of infusion reaction following standard infliximab infusions compared to 1-h infusions. We reanalysed the data by sequentially removing one study at a time. We then compared studies with few $(<2.5 \%)$ infusion reactions to those with a greater proportion $(\geq 2.5 \%)$ of infusion reactions. We also compared studies with small $(<300)$, medium (300-1000), or large $(>1000)$ numbers of infusions.

\section{Statistical Analyses}

A bivariate random effects regression model meta-analysis was performed with Stata 12.0 for Mac (StataCorp, College Station, TX, USA). Heterogeneity of relative risks (RR) across studies was evaluated with the Cochran's $Q$ statistic; $P<0.10$ represented significant heterogeneity. The $I^{2}$ statistic was also used to assess heterogeneity, with $<25 \%$ representing low heterogeneity and $>75 \%$ representing high heterogeneity. Assessment of publication bias was evaluated with visual inspection of funnel plot.

\section{RESULTS}

\section{Literature Search}

Of the 1535 studies identified in the literature search, 13 studies were included in our final analyses (Figure 1). The authors of two studies that were initially excluded due to lack of published data were contacted and provided additional data, so the studies were included in our final analyses. ${ }^{17,21}$

Three studies met all inclusion and exclusion criteria except that they included the number of patients receiving standard and rapid infliximab infusions rather than the number of infusions. ${ }^{15}, 17,18$ These studies were included in the per-patient analysis of the primary outcome only and in none of the other secondary meta-analyses. One study could not be included in the per-patient analysis because it included only infusion-level data. ${ }^{26}$ One additional study was not included in the per-patient analysis of the primary outcome (standard infusions vs. 1-h infusions) because it only included 30- to 45-min rapid infusions. ${ }^{21}$ There was $100 \%$ agreement between reviewers 


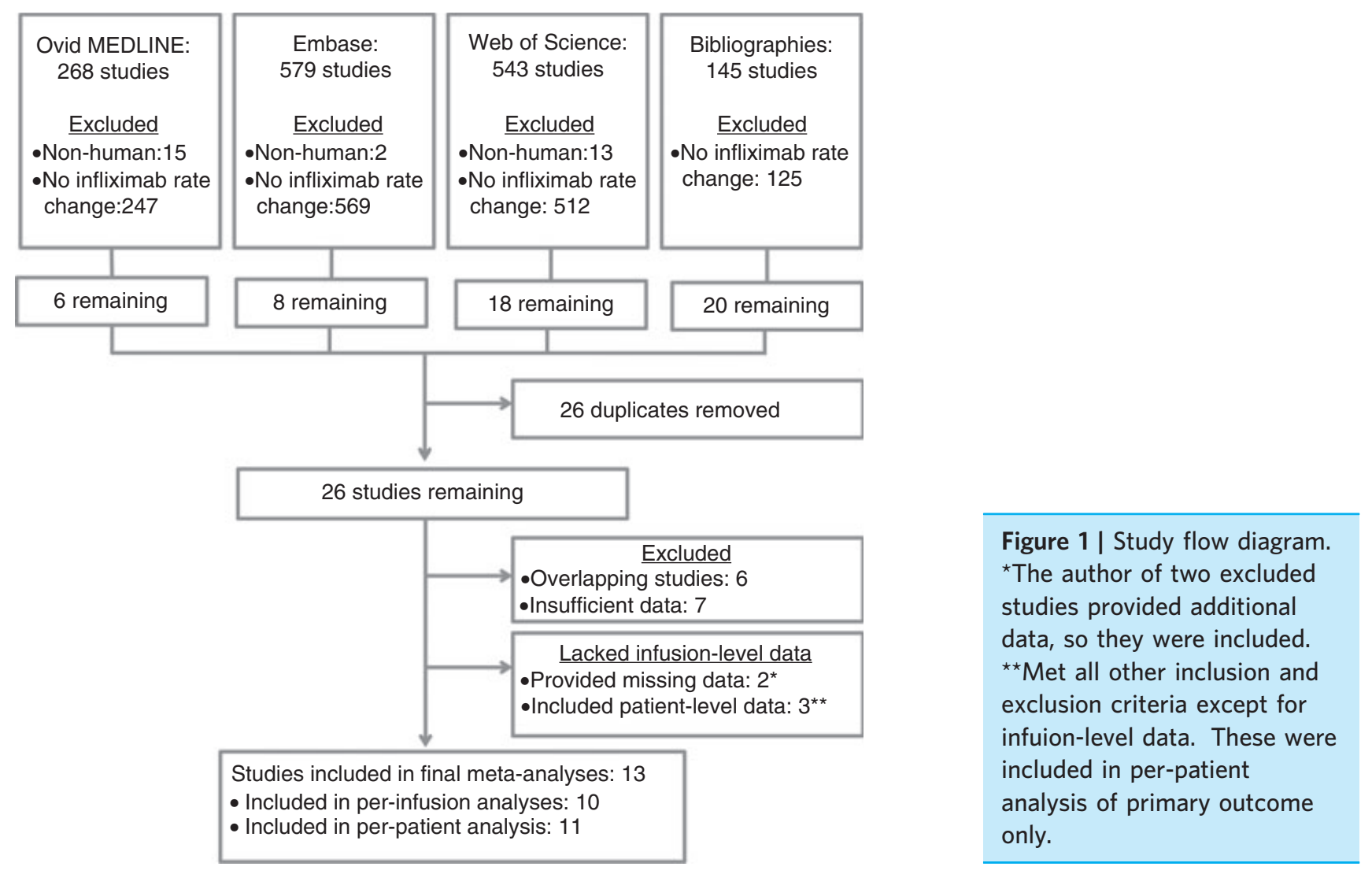

(HCN, MPR) on selection of studies. Design of the selected studies is summarised in Table 1.

\section{Study Characteristics}

The 10 studies with infusion-level data comprised 13147 standard infliximab infusions and 8497 rapid infusions. Of the rapid infusions, there were 7294 infusions of 1-h duration and 1203 infusions of 30- to 45-min duration. Selected study characteristics are summarised in Table 2.

\section{Quality Assessment}

The quality assessment of all included studies is summarised in Table 3. Seven of the studies were considered to be of either medium or high quality. ${ }^{16,20-23,25,27}$ Of the 13 reviewed studies, four disclosed conflict of interest. $^{16,17,24,27}$

\section{Standard vs. 1-h Infusions}

Infusion reactions occurred in 282 of 12922 (2.2\%) standard infliximab infusions and in 69 of $7294(0.9 \%)$

Table 1 | Design of selected studies

\begin{tabular}{lllll}
\hline Author, year (location) & $\begin{array}{l}\text { Prospective vs. } \\
\text { retrospective? }\end{array}$ & $\begin{array}{l}\text { Historical control vs. } \\
\text { true control? }\end{array}$ & Cross-over? & Peer reviewed? \\
\hline Bañuelos-Ramírez, 2007 (México) & Prospective & True control & No & Yes \\
Befrits, 2008 (unspecified) & Prospective & Historical control & No & No - Abstract \\
Belhassan, 2013 (France) & Retrospective & Historical control & Yes & Yes \\
Bhat, 2010 (Ireland) & Retrospective & Historical control & Yes & Yes \\
Breynaert, 2011 (Belgium) & Retrospective & Historical control & Yes & Yes \\
Buch, 2006 (England) & Retrospective & Historical control & Yes & Unclear - Letter to Editor \\
Clare, 2009 (England) & Prospective & Historical control & Yes & Yes \\
El Miedany, 2011 (England) & Retrospective & Unknown & Unknown & No - Abstract \\
Lee, 2011 (Canada) & Prospective & True control & No & Yes \\
Rojany, 2006 (unspecified) & Retrospective & Historical control & No & No - Abstract \\
Saxena, 2011 (unspecified) & Prospective & Historical control & Yes & No - Abstract \\
Shergy, 2002 (US) & Prospective & True control & Yes & Yes \\
Yeckes, 2009 (US) & Retrospective & Historical control & Yes & Yes \\
\hline
\end{tabular}




\begin{tabular}{|c|c|c|c|c|c|c|c|c|}
\hline Author & Age (years) & Disease & $\begin{array}{l}\text { Concomitant } \\
\text { medications }\end{array}$ & $\begin{array}{l}\text { Routine } \\
\text { premedication }\end{array}$ & $\begin{array}{l}\text { Infliximab } \\
\text { dose } \\
(\mathrm{mg} / \mathrm{kg})\end{array}$ & $\begin{array}{l}\text { No. of } \\
\text { standard } \\
\text { infusions } \\
\text { prior to } \\
\text { starting } \\
\text { rapid } \\
\text { infusions }\end{array}$ & $\begin{array}{l}\text { Duration of } \\
\text { rapid } \\
\text { infliximab } \\
\text { infusions } \\
\text { tested }\end{array}$ & $\begin{array}{l}\text { Subtypes } \\
\text { of infusion } \\
\text { reactions } \\
\text { studied }\end{array}$ \\
\hline $\begin{array}{l}\text { Bañuelos- } \\
\text { Ramírez }\end{array}$ & $\mathrm{N} / \mathrm{A}$ & RA, SA & $\begin{array}{l}\text { Some on MTX, } \\
\text { steroids }^{\star}\end{array}$ & None & $1.5-3$ & 0 & $30-45 \mathrm{~min}$ & $N / A$ \\
\hline Befrits & $\begin{array}{l}37 \\
\text { (median) }\end{array}$ & $\mathrm{IBD}, \mathrm{SA}$ & $\begin{array}{l}\text { Some on AZA, } \\
\text { steroids* }\end{array}$ & $\mathrm{N} / \mathrm{A}$ & $\mathrm{N} / \mathrm{A}$ & 4 & $1 \mathrm{~h}$ & $\mathrm{~N} / \mathrm{A}$ \\
\hline Belhassan & $\begin{array}{l}16-89 \\
\text { (range) }\end{array}$ & $\mathrm{IBD}$ & $\begin{array}{l}\text { Some on AZA, } \\
\text { MTX, steroids* }\end{array}$ & $\begin{array}{l}\text { All received } \\
\mathrm{IV} \mathrm{HC}\end{array}$ & $5-10$ & 3 & $1 \mathrm{~h}$ & $\begin{array}{l}\text { Acute } \\
\text { mild, } \\
\text { acute } \\
\text { severe, } \\
\text { delayed }\end{array}$ \\
\hline Bhat & $\mathrm{N} / \mathrm{A}$ & $\mathrm{IBD}$ & $\begin{array}{l}\text { Some on AZA, } \\
M T X \text {, and/or } \mathrm{MP}^{\star}\end{array}$ & $\begin{array}{l}\text { All received } \\
\text { PO loratidine; } \\
\text { IV HC in } \\
\text { subset of } \\
\text { patients }^{\star}\end{array}$ & 5 & 4 & $1 \mathrm{~h}, 30 \mathrm{~min}$ & $\begin{array}{l}\text { Delayed, } \\
\text { severe }\end{array}$ \\
\hline Breynaert & $\begin{array}{l}40 \\
\text { (median) }\end{array}$ & $\mathrm{IBD}$ & $\begin{array}{l}\text { Some on AZA, } \\
\text { MTX, MP, and/or } \\
\text { steroids* }^{*}\end{array}$ & $\begin{array}{l}\text { IV HC and CZ } \\
\text { in specified } \\
\text { subset } \\
\text { of patients }\end{array}$ & 5 & 4 & $1 \mathrm{~h}$ & $\begin{array}{l}\text { Delayed, } \\
\text { severe }\end{array}$ \\
\hline Buch & $\begin{array}{l}22-77 \\
\text { (range) }\end{array}$ & RA, SA, PA & $\begin{array}{l}\text { All on MTX and/or } \\
\text { leflunomide }\end{array}$ & $\begin{array}{l}\text { Some received } \\
\mathrm{IV} \mathrm{HC} \\
\text { and } \mathrm{CP}^{\star}\end{array}$ & $3-5$ & 4 & $1 \mathrm{~h}, 30 \mathrm{~min}$ & Severe \\
\hline Clare & $\begin{array}{l}\text { 14-91 } \\
\text { (range) }\end{array}$ & $\mathrm{IBD}$ & $\begin{array}{l}\text { Some on AZA, } \\
\text { MTX, MP, MMF, } \\
\text { and/or steroids* }\end{array}$ & $\begin{array}{l}\text { Some received } \\
\text { IV HC } \\
\text { and/or } \mathrm{CP}^{\star}\end{array}$ & $5-10$ & 4 & $1 \mathrm{~h}, 30 \mathrm{~min}$ & $\begin{array}{l}\text { Delayed, } \\
\text { severe }\end{array}$ \\
\hline El Miedany & $\begin{array}{l}23-78 \\
\text { (range) }\end{array}$ & RA, SA & $\begin{array}{l}\text { All on DMARD, } \\
\text { mainly MTX, } \\
\text { SZA, leflunomide }\end{array}$ & $\begin{array}{l}\text { Some received } \\
\text { IV HC and } \\
\text { antihistamine* }\end{array}$ & $\mathrm{N} / \mathrm{A}$ & 4 & $1 \mathrm{~h}$ & $\begin{array}{l}\text { Mild, } \\
\text { moderate, } \\
\text { delayed }\end{array}$ \\
\hline Lee & $\mathrm{N} / \mathrm{A}$ & $\begin{array}{l}\text { IBD, RA, SA, } \\
\text { psoriasis }\end{array}$ & $\begin{array}{l}\text { AZA, MTX, } \\
\text { and/or MP }\end{array}$ & $\begin{array}{l}\text { IV HC in } \\
\text { specified subset } \\
\text { of patients }\end{array}$ & $3-5$ & 3 & $1 \mathrm{~h}$ & $\mathrm{~N} / \mathrm{A}$ \\
\hline Rojany & Adult & $\mathrm{IBD}$ & $\begin{array}{l}\text { Some on } \\
\text { unspecified } \\
\text { immunomodulators* }\end{array}$ & $\mathrm{N} / \mathrm{A}$ & $\mathrm{N} / \mathrm{A}$ & 4 & $1 \mathrm{~h}$ & $\begin{array}{l}\text { Delayed, } \\
\text { severe }\end{array}$ \\
\hline Saxena & $\mathrm{N} / \mathrm{A}$ & $\mathrm{IBD}$ & $\mathrm{N} / \mathrm{A}$ & $\begin{array}{l}\text { All received } \\
\text { premedication, } \\
\text { but medication } \\
\text { not specified }\end{array}$ & $\mathrm{N} / \mathrm{A}$ & 4 & $1 \mathrm{~h}, 30 \mathrm{~min}$ & Severe \\
\hline Shergy & $\geq 18$ & RA & $\begin{array}{l}\text { All on MTX; } \\
\text { some on steroids } \\
\text { and/or unspecified } \\
\text { DMARDs }\end{array}$ & $\mathrm{N} / \mathrm{A}$ & 3 & 4 & $1 \mathrm{~h}$ & $\mathrm{~N} / \mathrm{A}$ \\
\hline Yeckes & $\begin{array}{l}12-21 \\
\text { (range) }\end{array}$ & $\mathrm{IBD}$ & $\begin{array}{l}\text { All on AZA, MTX, } \\
\text { and/or MP }\end{array}$ & $\begin{array}{l}\text { Some received } \\
\text { DP and } \\
\text { IV } \mathrm{MP}^{\star}\end{array}$ & $5-10$ & $3-4$ & $1 \mathrm{~h}$ & Severe \\
\hline
\end{tabular}

N/A, data not available; RA, rheumatoid arthritis; SA, spondylarthropathy; IBD, inflammatory bowel disease; PA, psoriatic arthritis; MTX, methotrexate; AZA, azathioprine; MP, mercaptopurine; DMARD, disease-modifying antirheumatic drug; MMF, mycophenolate; $\mathrm{HC}$, hydrocortisone; $\mathrm{MP}$, methylprednisolone; $\mathrm{DP}$, diphenhydramine; $\mathrm{CP}$, chlorpheniramine; $\mathrm{CZ}$, cetirizine; IFX, infliximab; $\mathrm{PO}$, oral; IV, intravenous.

* Not specified which patients received medication. 
Table 3 | Assessment of study quality using Newcastle-Ottawa quality scale for cohort studies and ad hoc quality criteria

\begin{tabular}{|c|c|c|c|c|c|c|c|c|c|c|c|c|c|c|}
\hline \multirow{2}{*}{ Author } & \multicolumn{4}{|c|}{ Selection } & \multicolumn{2}{|c|}{ Comparability } & \multicolumn{3}{|c|}{$\begin{array}{l}\text { Outcome } \\
\text { assessment }\end{array}$} & \multirow{2}{*}{$\begin{array}{l}\text { Global NOQS } \\
\text { assessment }\end{array}$} & \multicolumn{4}{|c|}{ Ad hoc criteria } \\
\hline & 1 & 2 & 3 & 4 & 1 & 2 & 1 & 2 & 3 & & 1 & 2 & 3 & 4 \\
\hline Bañuelos-Ramírez & * & $*$ & * & * & * & $*$ & * & $*$ & * & $\mathrm{HQ}$ & $*$ & $*$ & * & \\
\hline Befrits & * & & & * & & & * & * & * & LQ & & * & & \\
\hline Belhassan & $*$ & * & * & $*$ & & * & * & * & & MQ & $*$ & $*$ & $*$ & * \\
\hline Bhat & * & * & * & $*$ & * & & * & * & & MQ & $*$ & * & * & \\
\hline Breynaert & * & * & * & * & * & & * & * & & $M Q$ & $*$ & * & * & \\
\hline Buch & * & & & $*$ & $*$ & & * & * & & LQ & $*$ & * & * & * \\
\hline Clare & * & * & * & $*$ & * & & * & * & & $M Q$ & $*$ & * & * & \\
\hline El Miedany & * & * & * & $*$ & & & * & * & & LQ & & * & * & * \\
\hline Lee & * & * & $*$ & $*$ & & & * & * & & LQ & $*$ & * & * & \\
\hline Rojany & * & * & * & * & & & * & * & & LQ & & & & \\
\hline Saxena & * & * & & * & * & & * & * & & LQ & & & * & \\
\hline Shergy & * & & $*$ & $*$ & * & & * & * & * & $M Q$ & $*$ & * & & \\
\hline Yeckes & * & * & $*$ & $*$ & * & & * & * & & MQ & $*$ & * & * & * \\
\hline
\end{tabular}

1-h infusions. Meta-analysis of per-infusion data across nine studies demonstrated decreased risk of infusion reaction with 1 -h infusions compared to standard infusions with a RR of 0.48 [95\% confidence interval (CI) $0.28-0.83 ; P=0.009$ ] (Figure 2a). There was moderate evidence of heterogeneity between studies $\left(I^{2}=61.2 \%\right.$; Cochran's $Q 17.8, P=0.01$ ). There was little evidence of publication bias as demonstrated by visual inspection of the funnel plot (see Figure S1).

Eleven studies included the number of infusion reactions per patient in standard vs. 1-h infusions. A total of 181 of 2074 patients $(8.7 \%)$ receiving standard infusions and 95 of 1422 patients (6.7\%) receiving 1-h infusions experienced an infusion reaction. Meta-analysis of per-patient data also demonstrated decreased risk of infusion reaction with 1 -h infusions compared to standard infusions with a RR of 0.45 (95\% CI $0.25-0.80 ; P=0.007)$ (Figure 2b). There was significant evidence of heterogeneity between studies $\left(I^{2}=87.1 \%\right.$; Cochran's $Q 32.1$, $P=0.002$ ). The funnel plot (see Figure S2) was asymmetrical. It is notable that the smaller studies produced smaller effect sizes, resulting in a bias towards the null effect.

\section{Standard vs. $30-$ to $45-\mathrm{min}$ Infusions}

Infusion reactions occurred in 59 of 1807 (3.3\%) standard infliximab infusions and in 13 of 1203 (1.1\%) infusions of 30 - to 45 -min duration. Four of the studies ${ }^{19}, 22,24,25$ used a 30-min infusion protocol; one of the studies used a 30-min infusion protocol. ${ }^{21}$ Meta-analysis of per-infusion data demonstrated no significant difference in risk of infusion reaction between the groups $(\mathrm{RR}=0.48,95 \% \mathrm{CI}$ $0.10-2.27 ; P=0.35)$. There was moderate evidence of heterogeneity between studies $\left(I^{2}=58.8 \%\right.$; Cochran's $Q 7.3$; $P=0.06$ ) (Figure 3).

\section{Premedication Administration}

Premedication use was inadequately documented or inconsistently administered across most studies (Table 2). Only four studies provided clear documentation of consistent administration or non-administration of premedication. ${ }^{16,21,23,26}$

In the study by Belhassan et al., premedication with $200 \mathrm{mg}$ IV hydrocortisone was given prior to all infusions, both standard and 1 -h duration. ${ }^{16}$ Lee et al. described distinct groups of patients who consistently received premedication with corticosteroids. ${ }^{26}$ The RR of infusion reaction with standard vs. 1-h infusion with consistent premedication administration was 0.65 (95\% CI $0.28-1.50 ; P=0.31$ ) (see Figure S3).

In the study by Breynaert et al., no premedication was given prior to any infusion for patients in the 1-h infusion group. ${ }^{23}$ Patients in the standard infusion group received premedication if they had a prior infusion reaction or if they had a prolonged dosing interval greater than 13 weeks. Therefore, no comparable data were available for rate of infusion reaction in patients who exclusively received no premedication with both standard and 1-h infusions. 
Meta-analysis: rapid infliximab infusions are safe

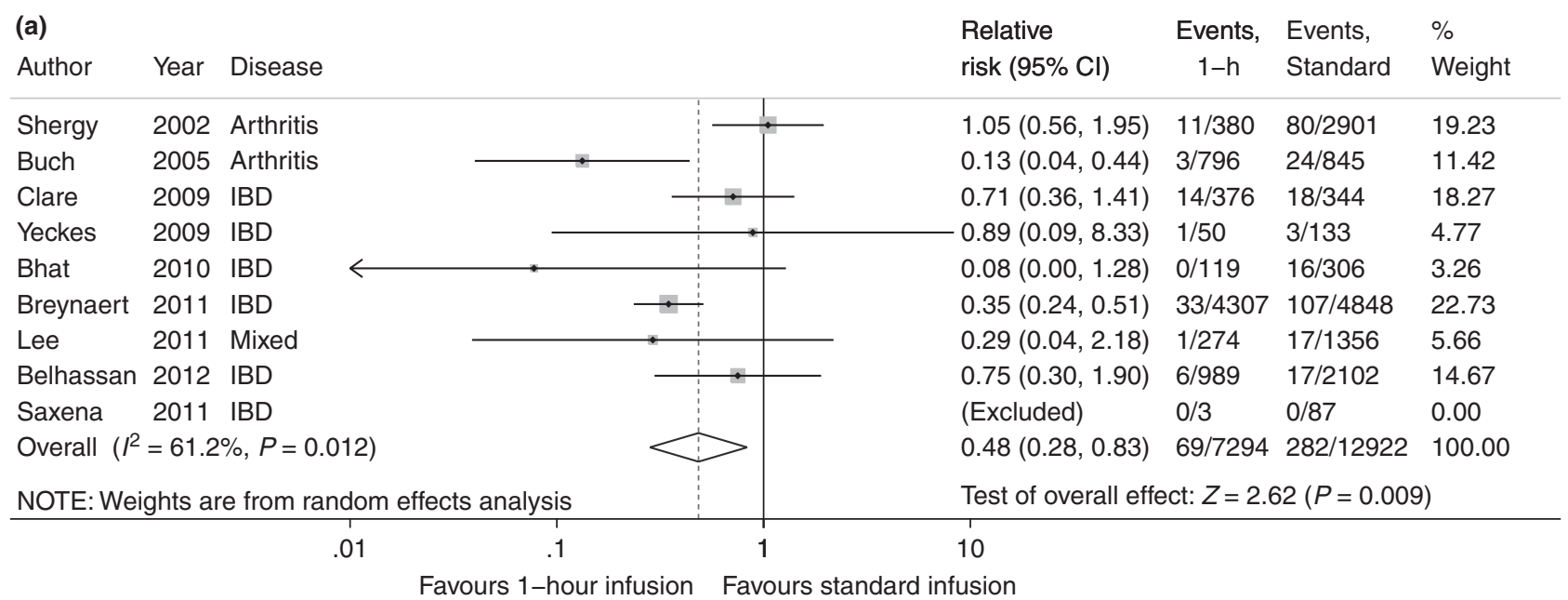

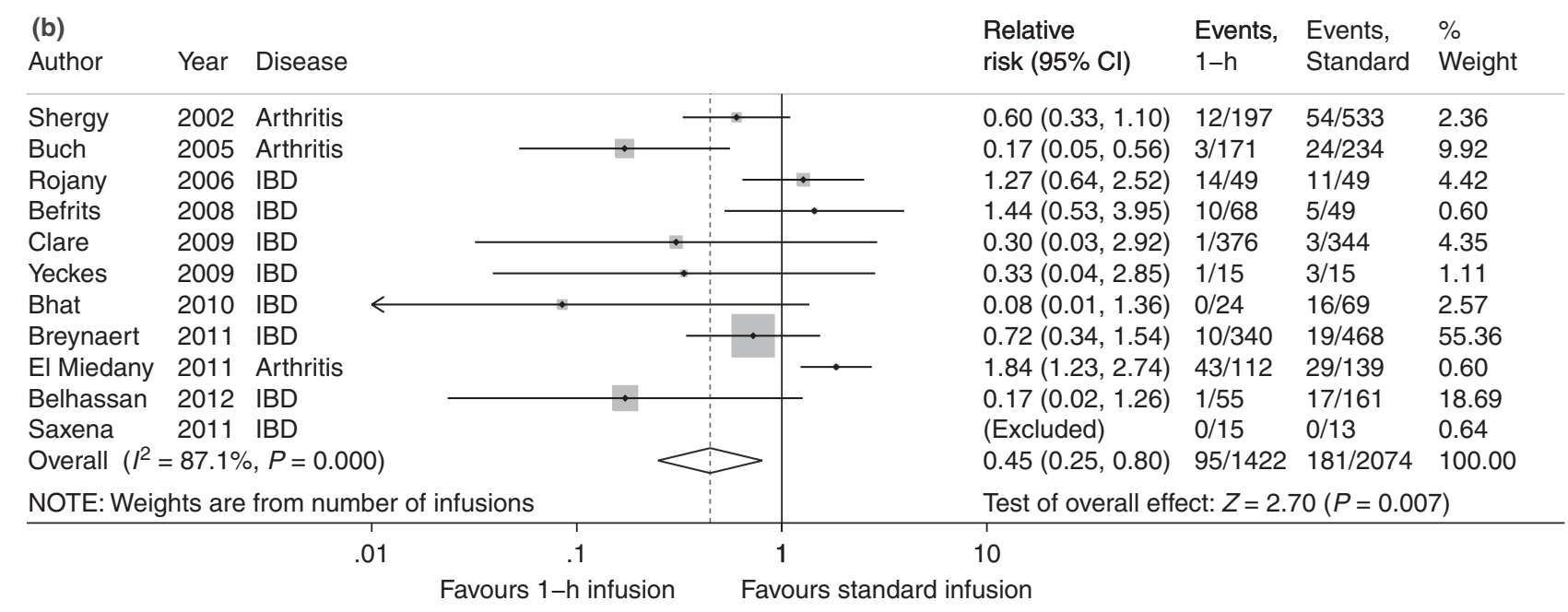

Figure 2 | Infusion reactions in standard vs. 1-h infliximab infusions. Results of (a) per-infusion analysis and (b) perpatient analysis. IBD, inflammatory bowel disease.

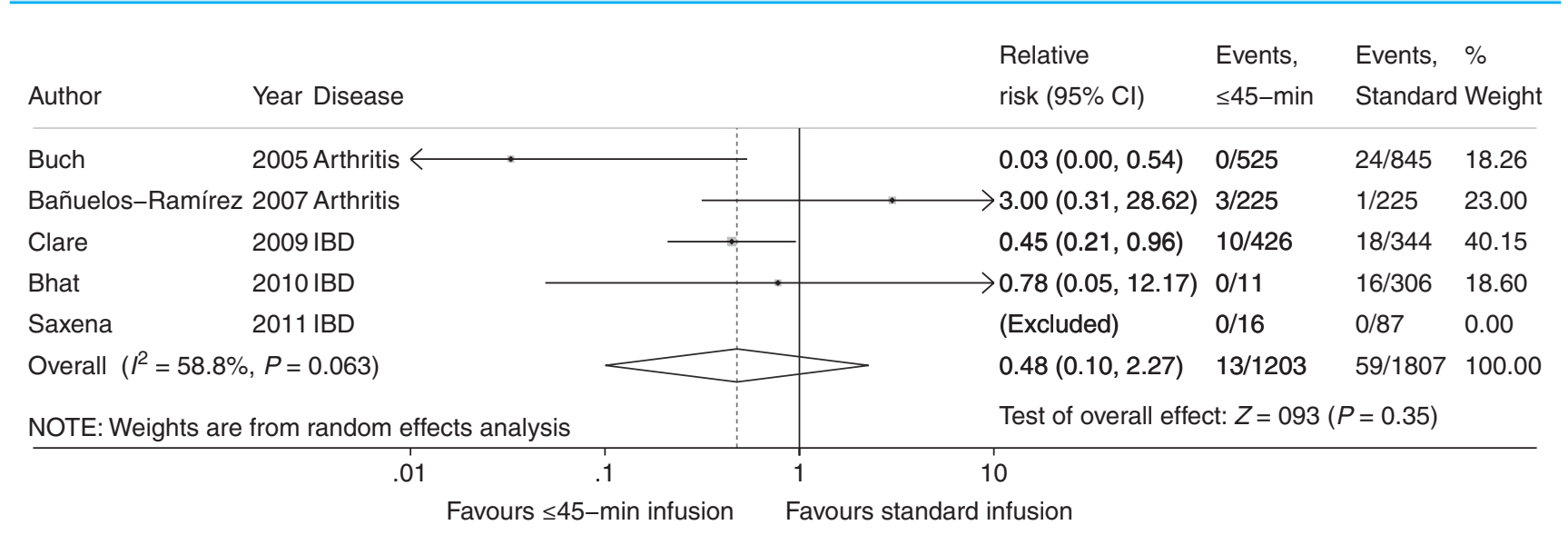

Figure 3 | Infusion reactions in standard vs. $30-$ to $45-$ min infliximab infusions.

In the six remaining studies in which premedication was inadequately documented or inconsistently administered, the pooled risk of infusion reaction was not different from that of those studies in which all patients received premedication prior to infusions $(\mathrm{RR}=0.49,95 \% \mathrm{CI}$ $0.19-1.17 ; P=0.11$ ) (see Figure S4). ${ }^{19}, 20,22,24,25,27$ 


\section{H. C. Neef et al.}

In the study by Bañuelos-Ramírez et al., no premedication was administered with any infliximab infusion, either standard or 30- to 45-min infusions, throughout the course of the study. ${ }^{21}$ The RR of infusion reaction in this study without premedication $(\mathrm{RR}=3.0,95 \%$ CI $0.31-$ 28.6; $P=0.34$ ) was not substantially different from the $R R$ of infusion reaction in meta-analysis of the four studies $^{19,22,24,25}$ that included 30-min infliximab infusions in which premedication was inadequately documented or inconsistently administered ( $\mathrm{RR}=0.28,95 \%$ CI $0.05-$ $1.64 ; P=0.16)$.

\section{Concomitant Medication Therapy}

In patients who received concomitant immune suppressing medications along with infliximab, infusion reactions occurred in 96 of 3205 (3.0\%) standard infliximab infusions and in 16 of 1255 (1.3\%) 1-h infusions. Concomitant immune suppressing therapies included one or more immunomodulator (mercaptopurine, methotrexate, azathioprine, or leflunomide) and/or ongoing oral steroid therapy (Table 2); the four studies included in the analysis were those in which all patients were clearly receiving at least one concomitant medication. Meta-analysis of per-infusion data demonstrated no significant difference in risk of infusion reaction between standard infliximab infusions and 1-h infusions ( $R R=0.53,95 \%$ CI $0.16-$ 1.72; $P=0.29$ ) (Figure 4). There was moderate evidence of heterogeneity between studies $\left(I^{2}=65.9 \%\right.$; Cochran's $Q$ 8.8; $P=0.03)$. There were insufficient data to make comparisons between different concomitant medications.

\section{Infusion Reaction Types}

Severe infusion reactions occurred in 18 of $6413(0.3 \%)$ standard infliximab infusions and in 2 of $5602(0.04 \%)$ 1-h infusions. Meta-analysis of per-infusion data across six studies demonstrated no significant difference in risk of severe infusion reaction between the groups $(\mathrm{RR}=0.33,95 \%$ CI $0.06-1.83 ; P=0.20$ ) (see Figure S5). There was moderate evidence of heterogeneity between studies $\left(I^{2}=38.7 \%\right.$; Cochran's Q 4.9; $P=0.18)$.

Delayed infusion reactions occurred in 39 of $5396(0.7 \%)$ standard infliximab infusions and in 8 of 4763 (0.2\%) 1-h infliximab infusions. Meta-analysis of per-infusion data across three studies showed decreased risk of delayed infusion reaction with 1-h infliximab infusions vs. standard infusions ( $\mathrm{RR}=0.27,95 \%$ CI $0.13-0.58 ; P=0.001$ ) (see Figure S6). There was minimal evidence of heterogeneity between studies $\left(I^{2}=0 \%\right.$; Cochran's $\left.Q 0.35 ; P=0.84\right)$.

\section{Primary Disease}

In seven studies with data limited to subgroups of patients with IBD, infusion reactions occurred in 172 of 8003 (2.1\%) standard infliximab infusions and in 55 of 5874 (0.9\%) 1-h infusions. Meta-analysis of per-infusion data demonstrated decreased risk of infusion reaction with 1-h infusions $\quad(\mathrm{RR}=0.49, \quad 95 \% \quad \mathrm{CI} \quad 0.31-0.76 ; \quad P=0.002)$ (Figure 5). There was evidence of heterogeneity between studies $\left(I^{2}=24.6 \%\right.$; Cochran's $\left.Q 17.8 ; P=0.01\right)$.

Four studies included data limited to subgroups of patients with other inflammatory conditions. One study did not provide data regarding 1 -h infliximab infusions. ${ }^{21}$ Of the remaining three studies, infusion reactions occurred in 111 of 5144 (2.2\%) standard infliximab infusions and in 14 of 1420 (1.0\%) 1 -h infusions. ${ }^{20,24,26}$ Meta-analysis of per-infusion data demonstrated no significant difference in risk of infusion reaction between the groups ( $\mathrm{RR}=0.40,95 \% \mathrm{CI} 0.07-2.11 ; P=0.28)$ (see

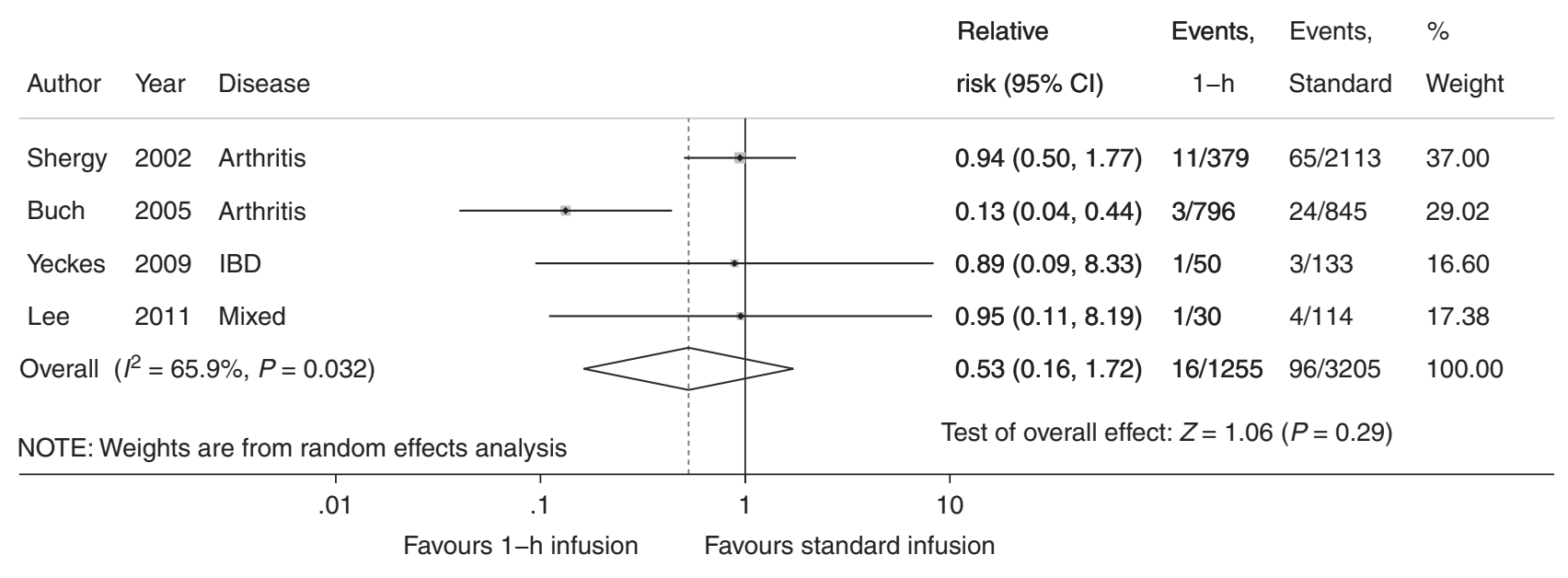

Figure 4 | Infusion reactions in standard vs. 1-h infliximab infusions with concomitant immunomodulator medications. 
Meta-analysis: rapid infliximab infusions are safe

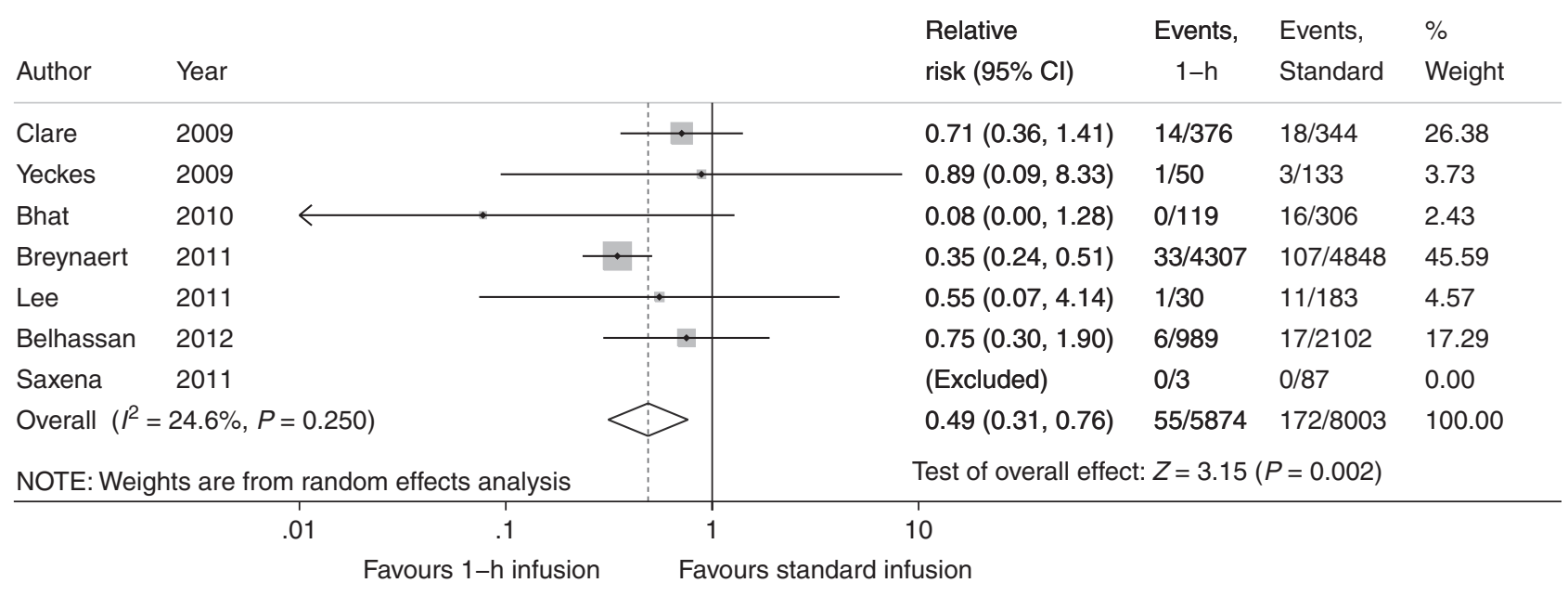

Figure 5 | Infusion reactions in standard vs. 1-h infliximab infusions in patients with inflammatory bowel disease.

Figure S7), with significant heterogeneity between studies $\left(I^{2}=79.7 \%\right.$; Cochran's $Q$ 9.8; $\left.P=0.008\right)$.

\section{Infliximab Dosing}

Five studies included data regarding high dose (5$10 \mathrm{mg} / \mathrm{kg}$ ) infliximab ${ }^{16,22,23,25,27}$ with which infusion reactions occurred in 161 of 7733 (2.1\%) standard infliximab infusions and in 54 of $5841(0.9 \%)$ 1-h infusions. Meta-analysis of per-infusion data demonstrated decreased risk of infusion reaction with 1 -h infusions $(\mathrm{RR}=0.50,95 \%$ CI $0.30-0.84 ; P=0.008) \quad($ see Figure S8). There was little evidence of heterogeneity between studies $\left(I^{2}=39.2 \%\right.$; Cochran's $\left.Q 6.44 ; P=0.17\right)$.

Two studies contained data regarding low dose $(<5 \mathrm{mg} / \mathrm{kg})$ infliximab. ${ }^{20,}{ }^{26}$ Meta-analysis of per-infusion data demonstrated no significant difference in risk of infusion reaction with 1 -h infusions $(\mathrm{RR}=1.00,95 \% \mathrm{CI}$ $0.55-1.84 ; P=1.00)$.

\section{Quality of Studies}

Seven studies were classified as either high or medium quality as defined by the Newcastle-Ottawa quality scale (Table 3). Six of these studies contained data comparing risk of infusion reaction in standard infliximab infusions to 1 -h infusions. ${ }^{16,20,22,23,25,27}$ One high-quality study included only data on 30 - to 45 -min infusions. ${ }^{21}$

Of the six high and medium quality studies containing data about 1-h infusions, meta-analysis of per-infusion data demonstrated no difference in the risk of infusion reaction $\quad(\mathrm{RR}=0.60, \quad 95 \% \quad \mathrm{CI} \quad 0.35-1.04 ; \quad P=0.07)$ between standard infusions (241 reactions of 10634 infusions; $2.3 \%$ ) and 1-h infusions (65 reactions of 6221 infusions; $1.0 \%)$. There was moderate evidence of hetero- geneity between studies $\left(I^{2}=60.7 \%\right.$; Cochran's $Q 12.5$; $P=0.03)$.

Of the three high and medium quality studies containing data about 30 - to $45-\mathrm{min}$ infliximab infusions, ${ }^{21,22,25}$ meta-analysis of per-infusion data demonstrated no difference in the risk of infusion reaction $(P=0.44)$ between standard infusions (35 reactions of 875 infusions; $4.0 \%)$ and 30 - to 45 -min infusions (13 reactions of 662 infusions; $2.0 \%$ ). There was minimal evidence of heterogeneity between the studies $\left(I^{2}=20.7 \%\right.$; Cochran's $\left.Q 2.57 ; P=0.28\right)$.

\section{Sensitivity Analysis}

Using sequential study-by-study removal, at each re-analysis of the primary outcome, the lower risk of infusion reaction with 1-h infliximab infusions compared to standard infusions persisted with one exception ${ }^{23}$; with removal of the study by Breynaert et al., no significant difference between the risk of infusion reaction in standard vs. 1-h infliximab infusions was demonstrated $(\mathrm{RR}=0.46,95 \%$ CI $0.20-1.03 ; P=0.06)$. Thus, with sequential removal of individual studies, none of the analyses demonstrated greater risk for rapid infusions compared with standard infusions.

To assess the possible influence of differing baseline risk of infusion reaction in different patient populations across studies, we compared studies documenting few $(<2.5 \%)$ infusion reactions with standard infusions ${ }^{16}, 19,23,26,27$ to those with greater incidence $(\geq 2.5 \%)$ of infusion reactions. ${ }^{20,22,24,25}$ When analysed regarding the primary outcome, studies with fewer infusion reactions with standard infusions had even fewer infusion reactions with 1-h infusions $(\mathrm{RR}=0.39,95 \% \mathrm{CI} 0.28-0.56, P<0.001)$ than 


\section{H. C. Neef et al.}

studies with greater proportions of infusion reactions with standard infusions $(\mathrm{RR}=0.43, \mathrm{CI} 0.16-1.19, P=0.10)$. When groups of studies of different sizes were assessed, there was no difference in the risk of infusion reaction between small studies of $<300$ total infusions ${ }^{19,21,27}$ (RR $=0.89$, CI 0.09-8.33; $P=0.92)$, medium-sized studies of $300-1000$ infusions $^{22,24,25}(\mathrm{RR}=0.25$, CI $0.06-$ $1.16 ; \quad P=0.08)$, and large studies of $>1000$ infusions $^{16,20,23,26}(\mathrm{RR}=0.58$, CI 0.29-1.16; $P=0.12)$. In no method of these sensitivity analyses were results contradictory to the primary outcome of our meta-analysis, confirming its stability. One-hour infliximab infusions remained non-inferior to standard infusions regarding risk of infusion reaction.

\section{DISCUSSION}

This study demonstrated that rapid infliximab infusions of 1-h or shorter duration, in selected patients who previously tolerated a minimum of three standard duration infusions, are not associated with an increased risk of infusion reaction when compared to the risk of reaction with standard 2- to 3-h duration infusions in the general population of unselected patients. In fact, a significantly lower risk of infusion reaction was found with shorter duration infusions. This was consistent when analysed both on a per-infusion and per-patient basis. We performed multiple subgroup analyses, each of which failed to demonstrate greater risk of infusion reaction with rapid infusions in selected patients who previously tolerated at least three standard infusions.

\section{Limitations of Study}

This study was limited by the common problems encountered in literature reviews. Relevant studies often included incomplete data, varying sources of bias and confounding variables that were difficult to account for. In the studies that did clearly define infusion reactions as 'severe', 'acute', or 'delayed', where these data were used for subgroup analyses, the definitions of these terms varied somewhat from study to study, making the results of these analyses less reliable. The majority of the studies were retrospective with historical control populations that mainly consisted of the same patients that subsequently entered rapid infliximab protocols. This introduces potential bias that limits our confidence in the apparent superiority of rapid infusions over standard infusions in selected patients who previously tolerated at least three standard infusions.

None of the studies were designed to blind patients to the rate of infusion. Although this may have introduced the possibility of misclassifying symptoms as infusion reactions, we postulate that this would tend to overestimate the number of infusion reactions. Premedicating patients prior to infliximab infusion with single dose antihistamine and/or steroid was one other potentially important confounding variable that may have modified the risk of infusion reaction. We were unable to account for this influence because the majority of studies did not document which patients received premedication. Furthermore, in many studies, patient attrition was not accounted for and could introduce a potential source of bias if patients preferentially left one group due to undocumented infusion reactions.

There is also the possibility that prior exposure to other biological agents or other immune suppressing medications may alter the likelihood of formation of antibodies to infliximab (ATI) or of infusion reactions. However, none of the papers identified in this search addressed prior medication usage or measured ATI.

Our use of infusion-level data rather than patientlevel data for this meta-analysis may lead to over- or under-confidence in the role infusion duration plays in infusion reactions. This may happen if an individual patient has a predisposition to infusion reaction, leading to an increased likelihood of reactions in all infusions for that given patient. Conversely, a patient who is on concomitant immunomodulator medication may have a lower incidence of infusion reaction. Thus, patient predisposition may dominate over patient-to-patient differences in infusion reaction. For this reason, we explored numerous post hoc subgroup analyses in our study.

Despite the above limitations, our meta-analysis sufficiently demonstrated the safety of rapid infliximab infusions with regard to infusion reactions.

\section{Implications of Study}

Rapid infliximab infusions may result in health care resource conservation. A recent study of a commercial US claims database showed that the average cost of administering infliximab for rheumatoid arthritis, including the cost of time spent monitoring the infusion, was $8.7 \%$ of the total cost of the drug. ${ }^{8}$ In a Canadian study, changing a patient from a 2 -h infliximab infusion with a $30-$ min post infusion observation period to a $1-\mathrm{h}$ infusion without an observation period led to a cost saving of $60 \%$ in fees related to administration of the medication. $^{26}$ In our institution, the average cost per infusion for administration of $300 \mathrm{mg}$ infliximab infused over $2 \mathrm{~h}$ without a post infusion observation period is US $\$ 7323$. Of this cost, US $\$ 858$ (11.7\%) is accrued due to drug administration and monitoring. If the infusion duration 
of each dose was reduced from 2 to $1 \mathrm{~h}$, we estimate a cost saving of US $\$ 317$ per infusion, reducing the cost of administration by $37 \%$ per infusion. This would lead to a cost savings of US $\$ 2140$ per patient per year for the standard protocol of infusions given every 8 weeks. In addition, rapid infusions would liberate space and health care staff in institutions with limited resources to accommodate more patients.

Rapid infliximab infusions are likely to be more convenient for patients, which may lead to improved adherence. Non-adherence with infliximab in the first year of therapy occurs in $25-35 \%$ of adults with Crohn's disease and is associated with substantially increased medical costs and rate of hospitalisations when compared to patients who are adherent with infliximab infusions. ${ }^{31,} 32$ Therefore, if adherence were improved with rapid infliximab infusions, this would further reduce medical costs and hospitalisation rates associated with poorly controlled disease.

In conclusion, our meta-analysis demonstrated that rapid infliximab infusions are well tolerated in patients who previously received at least three infliximab infusions of standard duration without an infusion reaction. These data support consideration of widespread use of 1-h infliximab infusions for selected patients who previously tolerated at least three to four standard duration infusions. This may conserve valuable health care resources and lead to improved adherence and quality of life in patients already receiving infliximab. Based on the results of our study, a well-designed, high-quality prospective randomised study may help provide a higher level of evidence on which to base widespread institution of rapid infliximab infusion.

\section{AUTHORSHIP}

Guarantor of article: Jeremy Adler.

Author contributions: H. Neef and J. Adler contributed to the study concept and design. H. Neef and M. Riebschleger performed the systematic review and study selection. H. Neef, M. Riebschleger and J. Adler contributed to data extraction. H. Neef and J. Adler contributed to data analysis. H. Neef drafted the manuscript. M. Riebs- chleger and J. Adler edited and critically reviewed the manuscript. All authors approved the final version of the manuscript.

\section{ACKNOWLEDGEMENTS}

We thank Dr David D. Bañuelos-Ramírez (Unidad Médica Alta Especialidad, Instituto Mexicano del Seguro Social, Puebla, México), Dr Zeitoun (Henri-Mondor Hospital, University Paris XII, Créteil, France) and Dr Yasser El Miedany (Darent Valley Hospital, Dartford, UK) for their assistance in clarifying details of their studies and providing certain original study data. We also thank Dr Peter D. R. Higgins for reviewing our manuscript and assisting with the clarity of communication. The above-mentioned individuals received no compensation for their contributions to this study.

Declaration of personal and funding interests: None.

\section{SUPPORTING INFORMATION}

Additional Supporting Information may be found in the online version of this article:

Figure S1. Studies with consistent administration of premedication prior to standard vs. 1-h infliximab infusions.

Figure S2. Studies with inconsistent documentation of administration of premedication prior to standard vs. 1-h infliximab infusions.

Figure S3. Severe infusion reactions in standard vs. 1-h infliximab infusions.

Figure S4. Delayed infusion reactions in standard vs. 1-h infliximab infusions.

Figure S5. Infusion reactions in standard vs. 1-h infliximab infusions in patients with rheumatoid arthritis, spondylarthropathy or psoriatic disease.

Figure S6. Infusion reactions in standard vs. 1-h infliximab infusions with high dose infliximab (5-10 mg/kg).

Figure S7. Infusion reactions in standard vs. 1-h infliximab infusions with low dose infliximab $(<5 \mathrm{mg} / \mathrm{kg})$.

Figure S8. Infusion reactions in standard vs. 1-h infliximab infusions in high and medium quality studies.

\section{REFERENCES}

1. Feagan BG, Reinisch W, Rutgeerts P, et al. The effects of infliximab therapy on health-related quality of life in ulcerative colitis patients. Am J Gastroenterol 2007; 102: 794-802.
2. Feldman SR, Gordon KB, Bala M, et al. Infliximab treatment results in significant improvement in the quality of life of patients with severe psoriasis: a double-blind placebo- controlled trial. Brit J Dermatol 2005; 152: $954-60$.

3. Maini R,St Clair EW, Breedveld F, et al. Infliximab (chimeric anti-tumour necrosis factor alpha monoclonal 
antibody) versus placebo in rheumatoid arthritis patients receiving concomitant methotrexate: a randomised phase III trial. ATTRACT Study Group. Lancet 1999; 354: 1932-9.

4. Hanauer SB, Feagan BG, Lichtenstein $\mathrm{GR}$, et al. Maintenance infliximab for Crohn's disease: the ACCENT I randomised trial. Lancet 2002; 359: 1541-9.

5. Hyams J, Crandall W, Kugathasan S, et al. Induction and maintenance infliximab therapy for the treatment of moderate-to-severe Crohn's disease in children. Gastroenterology 2007; 132: 863-73.

6. Adler J, Sandberg KC, Shpeen BH, et al. Variation in infliximab administration practices in the treatment of pediatric inflammatory bowel disease J Pediatr Gastroenterol Nutr 2013; 57: 35-8.

7. Remicade (Infliximab) prescribing information [package insert]. Horsham, PA: Janssen Biotech, Inc., 2013.

8. Ollendorf DA, Lidsky L. Infliximab drug and infusion costs among patients with Crohn's disease in a commercially-insured setting. Am J Ther 2006; 13: 502-6.

9. Wong BJ, Cifaldi MA, Roy S, Skonieczny DC, Stavrakas S. Analysis of drug and administrative costs allowed by U.S. Private and public third-party payers for 3 intravenous biologic agents for rheumatoid arthritis. JMCP 2011; 17: 313-20.

10. Van Assche G, Lewis JD, Lichtenstein GR, et al. The London position statement of the World Congress of Gastroenterology on Biological Therapy for IBD with the European Crohn's and Colitis Organisation: safety. Am J Gastroenterol 2011; 106: 1594-602.

11. Behm BW, Bickston SJ. Tumor necrosis factor-alpha antibody for maintenance of remission in Crohn's disease. Cochrane Database Syst Rev 2008; 1: CD006893.

12. Rutgeerts P, Feagan BG, Lichtenstein GR, et al. Comparison of scheduled and episodic treatment strategies of infliximab in Crohn's disease. Gastroenterology 2004; 126: 402-13.
13. Colombel JF, Sandborn WJ, Reinisch W, et al. Infliximab, azathioprine, or combination therapy for Crohn's disease. N Engl J Med 2010; 362: 1383-95.

14. Jacobstein DA, Markowitz JE, Kirschner BS, et al. Premedication and infusion reactions with infliximab: results from a pediatric inflammatory bowel disease consortium. Inflamm Bowel Dis 2005; 11: 442-6.

15. Befrits R, Malmström L, Forsell A, Bark L- $\AA$, Blomquist L. One hour infiximab infusion can replace two hour infusion in maintenance treatment of Crohns disease without shortcomings, in patients treated for up to three years. Gastroenterology 2008; 134: A402.

16. Belhassan M, Zeitoun JD, Lefevre JH, et al. Infliximab infusion time in patients with inflammatory bowel diseases: is longer really safer? Clin Res Hepatol Gastroenterol 2013; 37: 189-92.

17. El Miedany Y, Palmer D. Infliximab infusion therapy in inflammatory arthritis: assessment of the accelerated infusion protocol in comparison to the standard infusion approach. Rheumatology (Oxford) 2011; 50: 97-97.

18. Rojany M, Wegelin J, Trudeau W, Prindiville T. A rapid one-hour infusion of infliximab is well-tolerated gastroenterology. Gastroenterology 2006; 130: A212.

19. Saxena P, Ly C, Leong RW. Accelerated infliximab infusion protocols are safe. Gastroenterology 2011; 140: S276.

20. Shergy WJ, Isern RA, Cooley DA, et al. Open label study to assess infliximab safety and timing of onset of clinical benefit among patients with rheumatoid arthritis. J Rheumatol 2002; 29: 667-77.

21. Bañuelos-Ramírez D, Ramirez-Palma MM, Balcazar-Sanchez ME, SanchezAlonso S. Rapid application of infliximab. Efficacy complications. Reumatol Clin 2007; 3: 171-5.

22. Bhat S, Sharma D, Doherty P, Tham TC, Caddy GR. Are accelerated infliximab infusions safe in patients with inflammatory bowel disease? Inflamm Bowel Dis 2010; 16: 1922-5.

23. Breynaert C, Ferrante M, Fidder H, et al. Tolerability of shortened infliximab infusion times in patients with inflammatory bowel diseases: a single-center cohort study. Am J Gastroenterol 2011; 106: 778-85.

24. Buch MH, Bryer D, Lindsay S, ReesEvans B, Fairclough A, Emery P. Shortening infusion times for infliximab administration. Rheumatology (Oxford) 2006; 45: 485-6.

25. Clare DF, Alexander FC, Mike S, et al. Accelerated infliximab infusions are safe and well tolerated in patients with inflammatory bowel disease. Eur J Gastroenterol Hepatol 2009; 21: 71-5.

26. Lee TW, Singh R, Fedorak RN. A onehour infusion of infliximab during maintenance therapy is safe and well tolerated: a prospective cohort study. Aliment Pharmacol Ther 2011; 34: 181-7.

27. Yeckes AR, Hoffenberg EJ. Rapid infliximab infusions in pediatric inflammatory bowel disease. J Pediatr Gastroenterol Nutr 2009; 49: 151-4.

28. Stroup DF, Berlin JA, Morton SC, et al. Meta-analysis of observational studies in epidemiology: a proposal for reporting. Meta-analysis of observational studies in epidemiology (MOOSE) group. JAMA 2000; 283: 2008-12.

29. Wells GA, Shea B, O'Connell D, et al. The Newcastle-Ottawa Scale (NOS) for assessing the quality if nonrandomized studies in meta-analyses. Available at: http://www.ohri.ca/programs/ clinical_epidemiology/oxford.asp. Accessed March 28, 2013.

30. Liberati A, Altman DG, Tetzlaff J, et al. The PRISMA statement for reporting systematic reviews and meta-analyses of studies that evaluate health care interventions: explanation and elaboration. Ann Intern Med 2009; 151: W65-94.

31. Kane SV, Chao J, Mulani PM. Adherence to infliximab maintenance therapy and health care utilization and costs by Crohn's disease patients. $A d v$ Ther 2009; 26: 936-46.

32. Carter CT, Waters HC, Smith DB. Impact of infliximab adherence on Crohn's disease-related healthcare utilization and inpatient costs. $A d v$ Ther 2011; 28: 671-83. 